\title{
People, Communities, and Education at the Coast
}

\author{
Paula Sobral • José Carlos Ferreira • \\ Francisco Taveira Pinto
}

Received: 15 February 2012 / Accepted: 16 February 2012 / Published online: 11 May 2012

(C) Springer Science+Business Media B.V. 2012

This special issue titled "People,Communities, and Education at the Coast" of the Journal of Coastal Conservation, Planning and Management (JCCPM) gathers 8 of the submitted contributions to the 3rd International Conference on Coastal Conservation and Management in the Atlantic and Mediterranean (ICCCM10), held at Estoril, Portugal, in April 2010. The conference was attended by 800 participants from twenty-one countries, providing an expanded forum for scientists, engineers, planners and managers to discuss recent and new advances in scientific, technical, and socio-economic understanding of environmental issues related to coastal processes.

The eight papers in this issue cover several aspects from governance, social sustainability, public perception to environmental education.

The paper by Vasconcelos et al. presents the MARGov project, using as a case study the Marine Park Professor Luiz Saldanha (Portugal) to build a Model of Collaborative Governance for Marine Protected Areas, to empower local communities enabling them to be agents for change for the sustainable governance of the Ocean, through an eco-social dialogue

P. Sobral $(\bowtie)$

IMAR - Institute for Marine Research,

Faculty of Sciences \& Technology, Universidade Nova de Lisboa,

Campus da Caparica,

2829-516 Caparica, Portugal

e-mail: psobral@fct.unl.pt

\section{J. C. Ferreira}

Department of Environmental Sciences and Engineering,

Faculty of Sciences \& Technology, Universidade Nova de Lisboa,

Campus da Caparica,

2829-516 Caparica, Portugal

F. T. Pinto

Faculty of Engineering, University of Porto,

Rua Dr. Roberto Frias,

Porto 4200-465, Portugal supported by active participation. Kalisch examines the crowding effects in a coastal National Park in Germany, using the social carrying capacity concept as a tool to coastal recreation management.

Concerning coastal protection of sand dune systems in Portugal, Mendonça et al. describes an application of the Boussinesq-type COULWAVE model to study the wave hydrodynamics in the vicinity of a multi-functional artificial reef. From the public perception perspective, Baumann et al. examine the impact of the occurrence of jellyfish along the German Baltic coastline, show different methods to learn more about jellyfish accumulations and discuss information strategies in terms of improved beach management. Ferreira et al. present a beach profiling method to improve understanding of coastal processes by providing quantitative information on the spatial/ temporal evolution of beaches, which is crucial for coastal management and useful for environmental education. Quintela et al. focus on public perception of bathing users regarding Bathing Area quality in São Miguel (Portugal), namely litter, one of the top concerns of the users. Root-Bernstein et al. discuss and propose innovative and effective design solutions of multiple product proposals that would support a range of human-sea lion interactions in public parks and the fish market in Valdivia, Chile. Using local tidal records to identify relative sea level change, Powell et al. examine some of the key sources of error when working with historical tidal datasets in local geographic areas. They also identify the limitations of locally derived data thereby assisting in the determination of relative sea level trends that are of widespread value to infrastructure and policy makers.

We wish to thank the authors and the reviewers for their valuable efforts, and the Editor for his support in producing this special issue

Paula Sobral, José Carlos Ferreira and Francisco Taveira Pinto 